\title{
Large surface area sucrose-based carbons via template-assisted routes: Preparation, microstructure, and hydrogen adsorption properties
}

\author{
Jinjun Cai ${ }^{\mathrm{a}, \mathrm{b}}$, Menglong Yang ${ }^{\mathrm{a}}$, Yanlong Xing ${ }^{\mathrm{a}}$, Xuebo Zhao ${ }^{\mathrm{a}, *}$ \\ a Qingdao Institute of Bioenergy and Bioprocess Technology, Chinese Academy of Sciences, Qingdao 266101, PR China \\ ${ }^{\mathrm{b}}$ University of Chinese Academy of Sciences, Beijing 100049, PR China
}

\section{H I G H L I G H T S}

- Sucrose was selected as precursor to prepare carbons in the existence of USY zeolite.

- We studied the influence of USY zeolite on the pore structure of carbons.

- The specific surface area and pore width of these carbons can be easily adjusted.

- Hydrogen storage properties on these carbons were correlated with their pore structure.

\section{A R T I C L E I N F O}

\section{Article history:}

Received 5 June 2013

Accepted 25 December 2013

Available online 7 January 2014

\section{Keywords:}

Zeolites

Porous carbons

Hydrogen adsorption

Template carbonization

\section{G R A P H I C A L A B S T R A C T}

Sucrose-based porous carbons were prepared via template-assisted method. The presence of zeolite in carbonization will inhibit graphitic degrees to some extent and enlarge surface area and pore volume of carbons, and then improve hydrogen storage capacities.

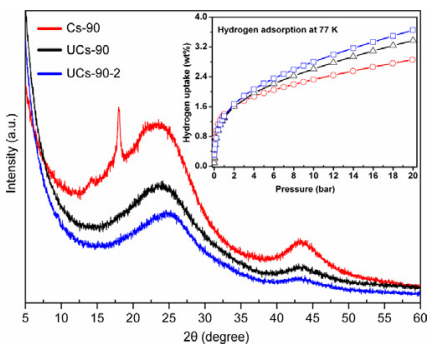

\begin{abstract}
A B S T R A C T
We report the preparation of sucrose-based nanoporous carbons via template-assisted routes using zeolite USY as the hard-template. Sulfuric acid-pretreated sucrose solution is polymerized and carbonized via adjusting the mass ratios of zeolite over sucrose and temperatures. Large surface area carbons with wide micropore size, developed mesoporosity and moderate storage capacity were obtained. We find that preparation parameters have great effects on the pore structure of carbons. Total pore volume of carbons develops with an increase of carbonization temperature and the presence of zeolite in carbonization processes can effectively enlarge the surface area and pore volume. However, the morphology of carbons is not transferred from zeolites, and micropore in the carbons is almost wholly from the sucrose precursor itself. The hydrogen adsorption properties of carbons at $77 \mathrm{~K}$ and 20 bar are further investigated in this work. Carbon with a surface area of $1200 \mathrm{~m}^{2} / \mathrm{g}$ exhibits a hydrogen storage capacity of up to $3.65 \mathrm{wt} \%$ at $77 \mathrm{~K}$ and 20 bar, and the hydrogen capacities at higher pressures are found to be much more correlated with surface area and micropore volume of carbons.
\end{abstract}

() 2014 Elsevier B.V. All rights reserved.

\section{Introduction}

Nowadays, the scarcity of energy resource and the environmental pollution in the evolution of human fuels have definitely aroused

\footnotetext{
* Corresponding author. Tel.: +86 532 80662728; fax: +86 53280662728

E-mail address: zhaoxb@qibebt.ac.cn (X. Zhao).
}

great attention towards searching for an alternative fuel [1]. Hydrogen is actually considered to be one of the most attractive energy carriers and fuels in the near future because its combustion creates neither air pollution nor green-house gas emission, and also with a heating value three times larger than petroleum [1-3]. For the most actual applications, however, the storage of hydrogen is the largest barrier to overcome. There is a growing interest in the development of new techniques for hydrogen storage, and the 
physisorption in carbon-based materials is one of the most promising methods available because of their fast kinetics, reversibility, and relatively low costs [4,5]. The surface areas and micropore volumes are found to be the most key parameters in dictating the hydrogen uptake in such materials. There are many studies to date have been conducted for hydrogen storage on various solidstate porous materials such as the activated carbons, zeolites, and metal-organic frameworks (MOF) [6-8], however, there are seldom materials can achieve the claims of DOE (Department of Energy, USA) criterion for the storage uptake on practical applications. The storage capacities of hydrogen on carbons are highly dependent on surface areas and porosities especially for microporosities, and the uptakes decrease rapidly at high temperature for the weak interaction between adsorbates and adsorbents. Therefore, the weak interaction of molecules physisorbed within pores is especially needed to be understood in order to optimize materials for hydrogen adsorption.

Porous carbons with well-developed pores have been used extensively in the area of catalysis, adsorption, separation, and electrode materials for their superior properties such as the high surface area, large pore volume, and extreme stability $[9,10]$. The past decade in particular has witnessed a rapidly growth in diverse applications, especially in the hydrogen storage [11-17]. In order to meet the requirements of hydrogen storage, a more refined control on the microporosities, surface chemistry and morphology of carbons is very desired [18]. Moreover, the preparation routes and precursor usually determine the ranges of physical properties for final carbons [19-21]. Therefore, there is no doubt that a sensible choice of precursors is one of the most critical issues for preparing carbons with high performance on hydrogen storage. Of late, many efforts have been conducted for preparing carbons with improved properties and lots of scientists have demonstrated that the existence of zeolites in carbonization has significant effects on the morphology, pore structure, and adsorptive behavior of carbons [22]. All previous reported data have definitely indicated a promising potential of the template-assisted method in hydrogen storage [23-25]. In general, templated-carbons were prepared via pyrolysis of precursor formed in highly ordered micro-channels or meso-channels of inorganic materials and followed the destruction of templates. In this way, pore structure of carbons can be largely manipulated via the selection of a proper inorganic template, precursor as well as pyrolytic conditions.

Sucrose is a kind of small organic molecules and has been widely used as precursor to prepare ordered mesoporous carbons using ordered silicas as hard-template [26-35]. In this paper, we report the preparation of porous carbons with sucrose as a precursor in the presence of USY zeolites via controlling the carbonization temperature and the mass ratio of zeolite to sucrose. Moreover, the adsorptive properties of hydrogen at $77 \mathrm{~K}$ on the carbons to 20 bar were also investigated. The purpose of this paper reported here is two-fold as follows: first to investigate the effects of preparation parameters on pores of carbons with an aim to better understanding the formation mechanism of pore structures; second to correlate the results of hydrogen storage at cryogenic temperature to the pore architecture of carbons.

\section{Experimental}

\subsection{Materials and preparation of carbons}

USY zeolite ( $\mathrm{H}$-form, $\mathrm{SiO}_{2} / \mathrm{Al}_{2} \mathrm{O}_{3}=10-13$, Xinhong Chemical Co., Ltd, China) was chose as the template after pre-calcination at $550^{\circ} \mathrm{C}$ for $6 \mathrm{~h}$ in air and used throughout in our experiment. Based on the information provided by manufacturer, the zeolite is an ultra-stable one which can preserve its crystal structure even up to $990^{\circ} \mathrm{C}$. Sucrose and sulfuric acid (AR, both purchased from Sinopharm Chemical Reagent Co., Ltd) were used as received. Nitrogen and hydrogen with purities above $99.999 \%$ for the gas adsorption measurements were provided by Qingdao Heli Gas Co., Ltd, China.

Sucrose-based carbons were prepared via a modified impregnation method [29,31]. Firstly, powdery zeolites dried under vacuum at $150^{\circ} \mathrm{C}$ for $6 \mathrm{~h}$ and then $1.0 \mathrm{~g}$ of zeolites were impregnated with an aqueous solution consisting of $1.0 \mathrm{~g}$ sucrose, $0.12 \mathrm{~g} \mathrm{H}_{2} \mathrm{SO}_{4}$, and $4.0 \mathrm{~g} \mathrm{H}_{2} \mathrm{O}$ under reduced pressure at $25^{\circ} \mathrm{C}$ and later pressure was restored to atmospheric pressure via introducing air. Secondly, the mixture of zeolite-sucrose solution were stirred for $10 \mathrm{~h}$ and then heated at 100 and $160^{\circ} \mathrm{C}$ for $6 \mathrm{~h}$, respectively. Composites of zeolite containing partially decomposed sucrose were immersed again with an aqueous solution consisting of $0.5 \mathrm{~g}$ sucrose, $0.06 \mathrm{~g} \mathrm{H}_{2} \mathrm{SO}_{4}$ and $4.0 \mathrm{~g} \mathrm{H}_{2} \mathrm{O}$ for stirring $10 \mathrm{~h}$. After heated again at $100^{\circ} \mathrm{C}$ for $6 \mathrm{~h}$ and followed at $160^{\circ} \mathrm{C}$ for $6 \mathrm{~h}$, the final brown-color composite were carbonized in a vertical quartz tube (i.d. $=16 \mathrm{~mm}$ ) under $\mathrm{N}_{2}$ flow at a rate of $5^{\circ} \mathrm{C} / \mathrm{min}$ to the fixed temperature $\left(600-1000^{\circ} \mathrm{C}\right)$ for $4 \mathrm{~h}$. In contrast, two samples were also carbonized at $900^{\circ} \mathrm{C}$ for $4 \mathrm{~h}$ via the same infiltration procedures with pure sucrose solution or doubled mass of zeolite to the first immersed sucrose. Finally, all black samples were treated with an excess amount of $40 \% \mathrm{HF}$ for $6 \mathrm{~h}$ and then refluxed in a concentrated $\mathrm{HCl}$ at $60^{\circ} \mathrm{C}$ for $3 \mathrm{~h}$. The obtained carbons were washed with copious quantities of distilled water and air-dried at $120^{\circ} \mathrm{C}$ overnight.

Carbons derived from the impregnation procedure that mass ratio of zeolite over the first impregnated sucrose is 1.0 were denoted as UCs-60, UCs-70, UCs-80, UCs-90, and UCs-100, corresponding to carbonization temperature of $600,700,800,900$ and $1000^{\circ} \mathrm{C}$, respectively. The sample carbonized at $900^{\circ} \mathrm{C}$ for $4 \mathrm{~h}$ via the same impregnation procedure with a doubled mass of zeolite to the first impregnated sucrose was denoted as UCs-90-2. Sample derived from a pure sucrose solution was denoted as Cs-90, referring to the carbonization temperature of $900^{\circ} \mathrm{C}$ for $4 \mathrm{~h}$.

\subsection{Characterization of porous carbons}

The structural feature of carbons was studied by the $\mathrm{X}$ ray diffractometer (XRD, Bruker D8) and Raman spectrometer (Renishaw-inVia Raman microscope, UK). The morphologies were performed with observations on a scanning electron microscopy (SEM, Hitachi S-4800). $\mathrm{N}_{2}$ sorption data were collected at $77 \mathrm{~K}$ on a static volumetric sorption analyzer (ASAP2020, Micrometrics, USA). The surface area was calculated using Brunauer-EmmettTeller (BET) method based on the adsorption data of $\mathrm{N}_{2}$ in the relative pressure $\left(p / p_{0}\right)$ range of $0.02-0.25$. The partial pressure range $(0.02-0.25)$ for the calculation of surface area was selected taking into accounts previous reports that lower partial pressure range (0.01-0.05) will overestimate surface area whereas partial pressure range (0.1-0.3) underestimate surface area [36,37]. Before $\mathrm{N}_{2}$ adsorption measurements, samples were degassed for $10 \mathrm{~h}$ at $300^{\circ} \mathrm{C}$.

\subsection{Hydrogen uptake measurements}

Hydrogen adsorption measurements were performed on an Intelligent Gravimetric Analyzer (IGA-001, Hiden), which is an ultrahigh vacuum system, and incorporates a microbalance capable of measuring weight with a resolution of $\pm 0.1 \mu \mathrm{g}$. The hydrogen uptakes were determined at $77 \mathrm{~K}$ over a pressure range to 20 bar and adsorption results were corrected for the buoyancy effect. Before adsorption measurements, samples were degassed $\left(10^{-7}\right.$ bar) at $200^{\circ} \mathrm{C}$ for $5 \mathrm{~h}$. 


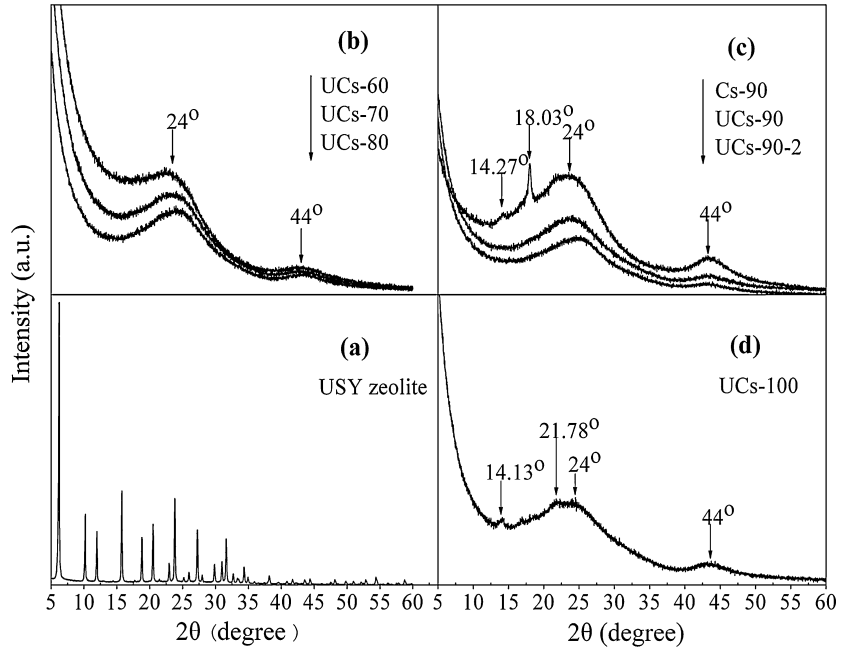

Fig. 1. Powder XRD patterns for the USY zeolite template and sucrose-based carbons.

\section{Results and discussions}

The XRD patterns for sucrose-based carbons obtained from different conditions are shown in Fig. 1. For comparison, XRD pattern of original USY zeolite is also included. It is clearly observed that all carbons exhibit two broad weak diffraction peaks at around $24^{\circ}$ and $44^{\circ}$ regardless of the preparation processes, attributing to the (002) and (101) diffractions from the turbostratic carbons, respectively $[4,30]$. The absence of sharp peaks indicates that sucrose-based carbons possess low crystallinity and most of them contain large proportion of amorphous structure. However, the graphitic degree of carbons is found to be largely dependent on carbonization temperature and mass ratio of zeolites to sucrose. For example, other weak peaks apart from the $24^{\circ}$ and $44^{\circ}$ happen to appear in UCs100 (Fig. 1d) while the Cs-90 has already showed some apparent peaks (Fig. 1c). A sharp peak at around $18^{\circ}$ in Cs-90 is the first time for observations and we speculatively believe that it maybe arise from other turbostaratic carbon contaminants [17,38]. In addition, the presence of USY zeolites in carbonization process can definitely inhibit the graphitization. This phenomenon maybe due to a fact that the sucrose solution can partly diffuse into micro-channels of zeolites and then the spatial limitation in channels will effectively prevent the formation of graphitic structures. However, the typical peak at around $6^{\circ}$ assigning to the (111) plane of USY zeolites is not observed in our present work, indicating that the transferability of structural orderings from zeolite for sucrose-based carbons is relatively low [30].

The porosities of USY zeolites and carbons are probed via $\mathrm{N}_{2}$ adsorption technique and corresponding $\mathrm{N}_{2}$ sorption isotherms are shown in Fig. 2. Detailed pore structure parameters of sucrosebased carbons are listed in Table 1 . The characteristic Type I isotherm of zeolites demonstrates its relatively large surface area and developed microporosities. However, a tiny hysteresis loop appeared at the higher pressure (e.g. $p / p_{0}=0.45-1.0$ ) supports the existence of narrow mesopores in the structure of zeolites which is maybe due to the formation of interparticle voids [14]. We can find that the $\mathrm{N}_{2}$ sorption profiles for carbons except for the Cs-90 are quite similar to each other (Fig. 2). They are all the combination of Type I and II isotherms with an apparent hysteresis loop over a wide pressure range [39], and exhibit a more rounded "knee" at the low relative pressure than USY zeolites and Cs-90, indicating that the carbons contain not only large amounts of micropores but also a portion of meso- or macro-pores with slit-like pores, which are probably due to an incomplete infiltration of precursor into

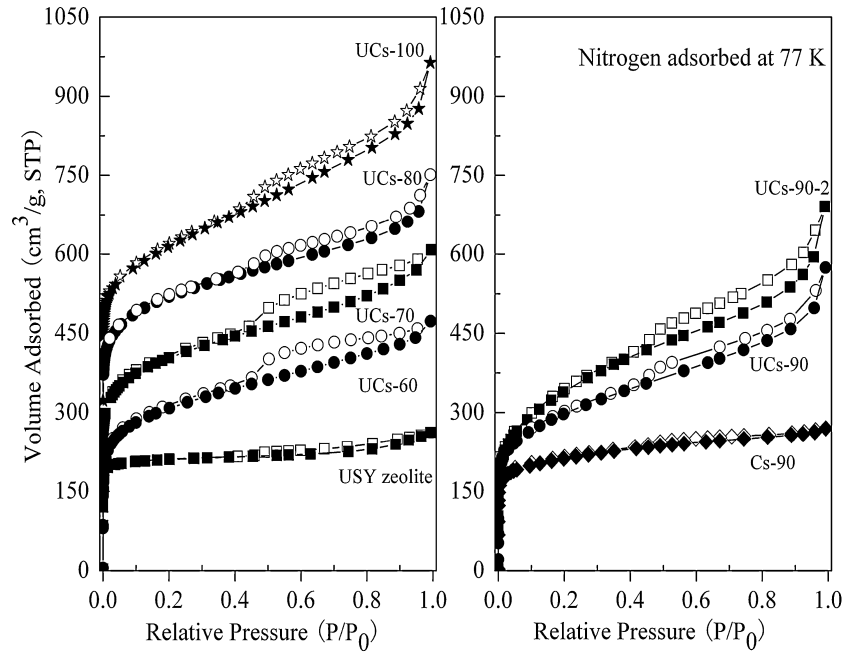

Fig. 2. The $\mathrm{N}_{2}$ adsorption (Filled symbols) and desorption (Open symbols) isotherms for USY zeolite template and sucrose-based carbons. For clarity, isotherms of UCs-70, UCs-80, and UCs-100 carbons are offset ( $y$-axis) by 80, 200, and 320, respectively.

micro-channels of zeolites [14,17,30]. All of these observations are also supported from the pore volume analyses in Table 1. We find that the quantities of mesopores and total pore volume are almost proportional to the carbonization temperature, though mesopores in carbons only have little contributions to the surface area (Table 1). It should be noted that hysteresis seems to become narrower at an elevated temperature under the same synthesis process, that is, the hysteresis loop in UCs-80, UCs-90, and UCs100 is obviously thinner than the one in UCs-60 and UCs-70. The narrow hysteresis loop indicates that the disordered mesopores are not isolated or entrapped within micropore structures but exposed to the external surface of the carbon particles [40]. For the Cs-90 sample in Fig. 2 derived from the pure sucrose solution, the sorption isotherm is a typical Type I isotherm, indicating mainly a microporous material.

The pore size distributions (PSDs) of carbons determined via the non-local density functional theory (NLDFT) model using the adsorption data of $\mathrm{N}_{2}$ are shown in Fig. 3, which are in good consistent with the results of adsorption isotherms presented in Fig. 2. It is very clearly that pore width in sucrose-based carbons
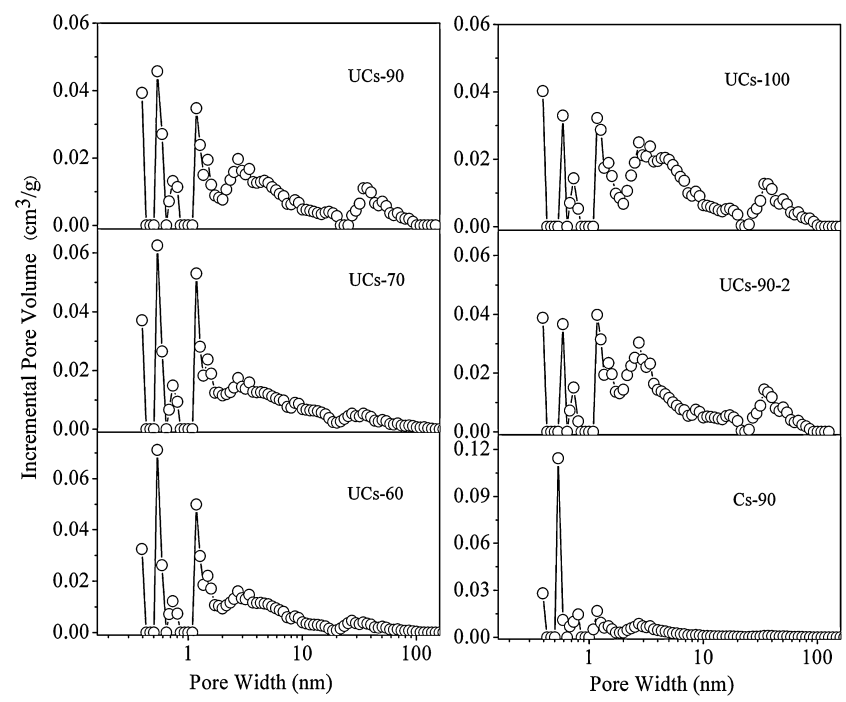

Fig. 3. Pore size distribution (PSD) curves obtained via applying NLDFT method to the $\mathrm{N}_{2}$ adsorption data of these sucrose-based carbons. 
Table 1

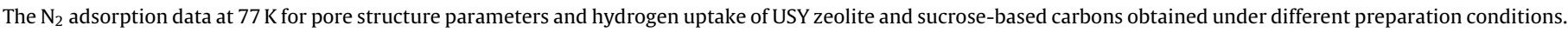

\begin{tabular}{|c|c|c|c|c|c|c|}
\hline Sample & $S_{\text {BET }}\left(\mathrm{m}^{2} / \mathrm{g}\right)^{\mathrm{a}}$ & $V_{\text {Total }}\left(\mathrm{cm}^{3} \mathrm{~g}^{-1}\right)^{\mathrm{b}}$ & $V_{\text {Micro }}\left(\mathrm{cm}^{3} \mathrm{~g}^{-1}\right)^{\mathrm{c}}$ & $V_{\text {Meso }}\left(\mathrm{cm}^{3} \mathrm{~g}^{-1}\right)^{\mathrm{d}}$ & $R_{\text {Micro }}(\%)^{e}$ & Hydrogen uptake (wt\%) \\
\hline USY zeolite & 701.5 & 0.405 & 0.304 & 0.101 & 0.75 & - \\
\hline UCs-60 & 1071.9 & 0.731 & 0.488 & 0.243 & 0.67 & $3.32(1.29)$ \\
\hline UCs-70 & 1127.2 & 0.817 & 0.498 & 0.319 & 0.61 & $3.52(1.43)$ \\
\hline UCs-80 & 1088.9 & 0.853 & 0.475 & 0.378 & 0.55 & $3.37(1.28)$ \\
\hline UCs-90 & 1038.4 & 0.888 & 0.433 & 0.455 & 0.49 & $3.37(1.30)$ \\
\hline UCs-100 & 1042.1 & 0.996 & 0.414 & 0.582 & 0.41 & $3.23(1.15)$ \\
\hline UCs-90-2 & 1218.6 & 1.068 & 0.458 & 0.610 & 0.43 & $3.65(1.34)$ \\
\hline Cs-90 & 723.2 & 0.417 & 0.324 & 0.093 & 0.77 & $2.85(1.39)$ \\
\hline
\end{tabular}

a Surface area is calculated via Brunauer-Emmet-Teller (BET) method at $p / p_{0}=0.02-0.25$.

b Total pore volume is estimated from the adsorption data of $\mathrm{N}_{2}$ at $p / p_{0}=0.996$.

c Micropore volume is calculated via the Dubinin-Radushkevich (DR) equation.

d Mesopore volume is derived by subtracting micropore volume from total pore volume.

e Ratio of micropore volume.

${ }^{\mathrm{f}}$ Hydrogen uptake is measured at $77 \mathrm{~K}$ and 20 bar via the gravimetric adsorption method, and the value in the parentheses is the hydrogen uptake at $77 \mathrm{~K}$ and 1 bar.

can be divided into four parts, that is, $<1 \mathrm{~nm}, 1-2 \mathrm{~nm}, 2-10 \mathrm{~nm}$, and $>10 \mathrm{~nm}$. Moreover, the relative amounts between different pore sizes change with the preparation conditions. In the range of pores having pore size less than $1.0 \mathrm{~nm}$, the PSD curves for all carbons are quite similar to each other regardless of the presence of USY zeolites in the preparation process or not, indicating that this proportion of micropores of carbons inherited wholly from sucrose precursor itself during its carbonization processes. This is due to the fact that the carbonization of oxygen-rich organic molecules such as sucrose will generate large amounts of gaseous species (e.g., $\mathrm{CO}_{2}$ and $\mathrm{H}_{2} \mathrm{O}$ ), resulting in the creation of considerable voids space (i.e., micropores) inside the carbon frameworks [40]. The PSD curves in the range of $1-2 \mathrm{~nm}$ with a maxima at around $1.4 \mathrm{~nm}$ for the carbons prepared in the presence of zeolites are very reasonable, and most probably transferred from the wall frameworks of zeolites via a comparison to Cs-90 [41]. In addition, the ranges of $2-10 \mathrm{~nm}$ and $>10 \mathrm{~nm}$ in pore size are apparently related to the carbonization temperature and the mass ratio of zeolites to sucrose. For example, the two samples, UCs-100 and UCs-90-2, have a maximum ratio of meso- and macro-pores in the ranges compared with other samples. From the data listed in Table 1, we can also conclude that carbonization with a higher temperature and more amounts of zeolite additives to sucrose appear to favor the larger pores and total pore volumes. We believe that the larger pores are created from the pore collapse during the etching processes in view that the sucrose binders between carbon particles may not be stable enough to maintain the carbon frameworks after the template is removed [30]. The Brunauer-Emmet-Teller (BET) specific surface areas and total pore volumes of the carbons derived in the presence of USY zeolites are of respectively up to $1038 \mathrm{~m}^{2} / \mathrm{g}$ and $0.88 \mathrm{~cm}^{3} \mathrm{~g}^{-1}$, which are much higher than the one in the absence of zeolite $\left(700 \mathrm{~m}^{2} / \mathrm{g}\right.$ and $\left.0.417 \mathrm{~cm}^{3} \mathrm{~g}^{-1}\right)$. Moreover, the surface area of sucrose-based carbons obtained in this work is also much larger than the previous reported data from the pure sucrose solution $\left(603 \mathrm{~m}^{2} / \mathrm{g}\right)$ [26], indicating that the use of zeolite additives in carbonization process is very helpful for enlarging the surface area of carbons. Indeed, the BET surface area of Cs-90, UCs-90, and UCs-90-2 increase gradually in turn. Therefore, it can be inferred that the presence of zeolite in carbonization process plays an important role in the development of carbon's pore structure, especially for the meso- and macro-pores.

Fig. 4 shows SEM images of the original USY zeolites and carbons with the aim to further investigate the effects of carbonization temperature and zeolite additives on the microstructure of carbons. As shown in Fig. 4, the USY zeolite exhibits well-resolved hexagonal crystal morphologies while carbons display a disordered morphology without any macroscopic structure replicated from the template, which was previously observed the replication in
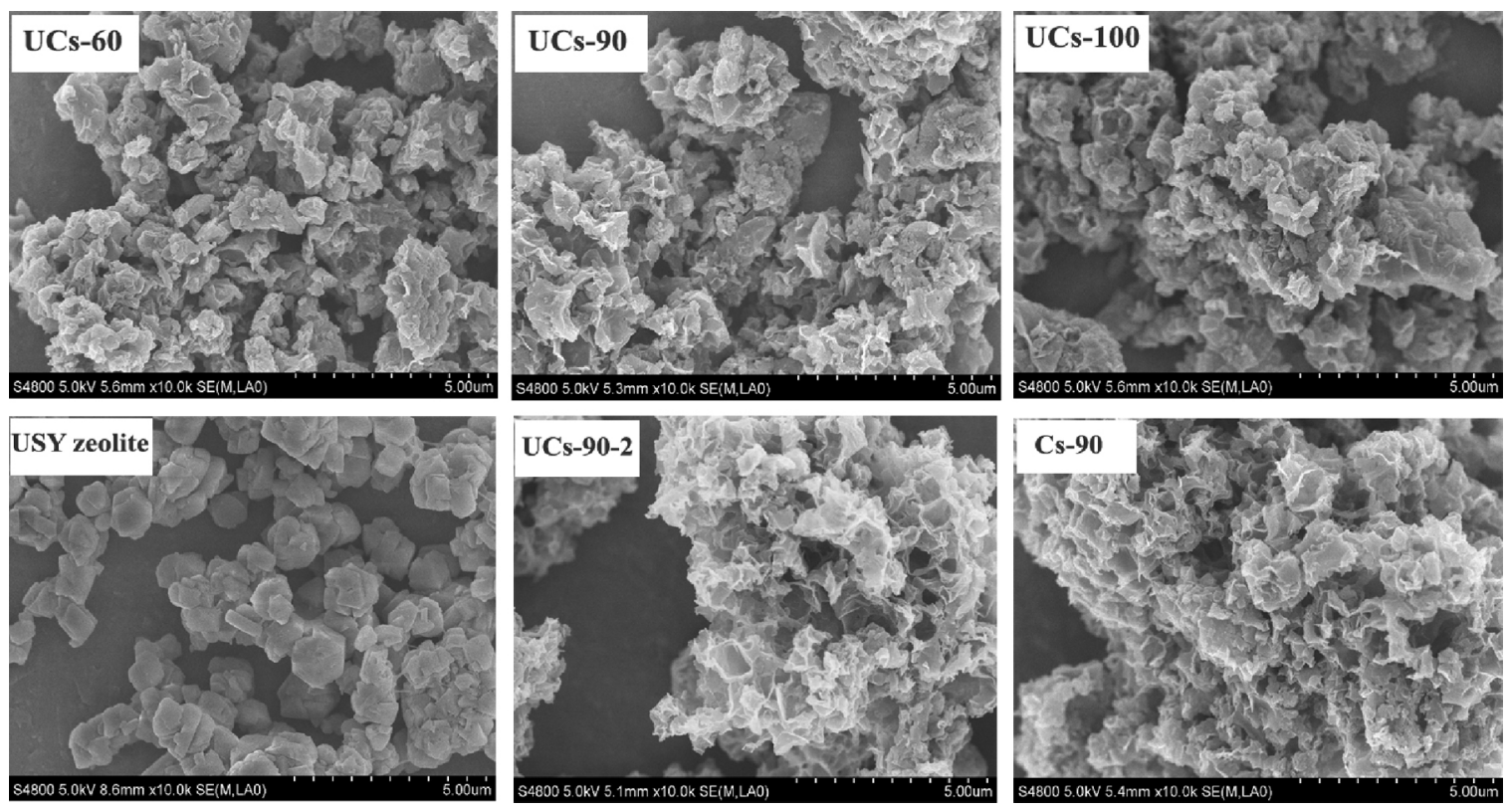

Fig. 4. Representative SEM pictures for USY zeolite template and sucrose-based carbons. 


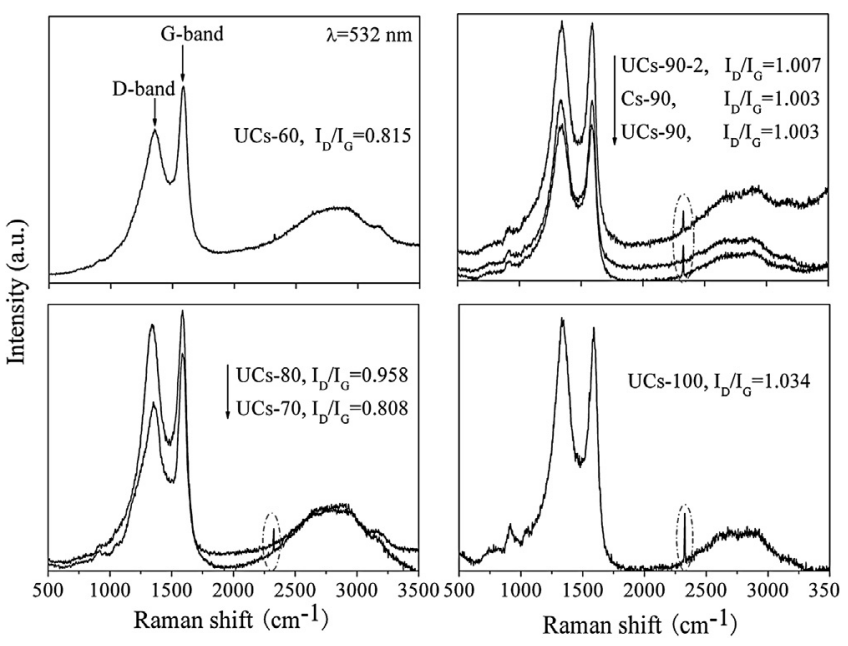

Fig. 5. Representative Raman spectra for the prepared sucrose-based carbons.

carbons derived from zeolite with other kinds of precursors $[4,38,42]$. Comparatively, Cs-90 and UCs-90-2 show well sheetgraphite-like structures with large interparticle voids on micrometer scale. The overall results of SEM images are in good accordance with the XRD results in Fig. 1 that carbons are largely amorphous.

The Raman spectroscopy is used to further illustrate the levels of graphitization of carbons and the corresponding results are show in Fig. 5. Raman spectra measurements are performed on a RenishawinVia Raman microscope excited with a $532 \mathrm{~nm}$ laser. It is very clearly that two prominent peaks located at around $1350 \mathrm{~cm}^{-1}$ (D-band) and $1590 \mathrm{~cm}^{-1}$ (G-band) can be found for all the sucrosebased carbons, ascribing to an imperfect structure of amorphous carbons and $C-C$ stretching vibration mode of graphene with $s p^{2}$ electronic configuration, respectively [26]. The relative intensity ratio between $\mathrm{D}$-band and G-band $\left(I_{\mathrm{D}} / I_{\mathrm{G}}\right)$ is usually partly utilized to evaluate the graphitic degrees of carbon-based materials. As can be seen from the Fig. 5 , the variations of $I_{\mathrm{D}} / I_{\mathrm{G}}$ are found and a universal observation is that the approximate value of $I_{\mathrm{D}} / I_{\mathrm{G}}$ increases with an increase of carbonization temperature. The phenomenon agrees well with that reported previously by other groups [26,42] and the graphitic degree of sucrose-based carbon in our present work is very poor even at an elevated carbonization temperature, indicating that the formation of some $s p^{3}$ electronic configurations for the carbon element in amorphous carbons [43]. Furthermore, an additional broad 2D-band around $2700 \mathrm{~cm}^{-1}$ and a sharp peak around $2300 \mathrm{~cm}^{-1}$ appear in all carbons, which are maybe attribute to the overtones and combinations of vibration modes for the graphitic layer $[44,45]$. Their appearance indicates the existence of some graphitic-graphene structures, and Raman data are in good agreement with the XRD and SEM observations.

The hydrogen adsorption isotherms of carbons $(77 \mathrm{~K}$ over pressure range $0-20$ bar), measured from the gravimetric analysis, are shown in Fig. 6. Detailed hydrogen storage capacities at pressure of 1 and 20 bar are listed in Table 1 . All the hydrogen adsorption isotherms are Type I in the IUPAC classification [39] and desorption isotherm (Inset Fig. 6) with virtually no hysteresis at $77 \mathrm{~K}$ confirmed from other hand that the hydrogen uptake on these carbons is totally reversible and impurities have not been adsorbed [5]. Especially, the adsorption uptakes of hydrogen at 1 bar vary between 1.1 and $1.4 I_{\mathrm{D}} / I_{\mathrm{G}}$ wt\%, which are very comparable to the previous observations on other sucrose-based carbons obtained from different preparation routes $[11,30]$. We believe that the trend in hydrogen uptakes is closely related to the textural properties of carbons and maybe also relate to the levels of graphitic degree. UCs-90-2 has both the highest surface area and total pore volume,

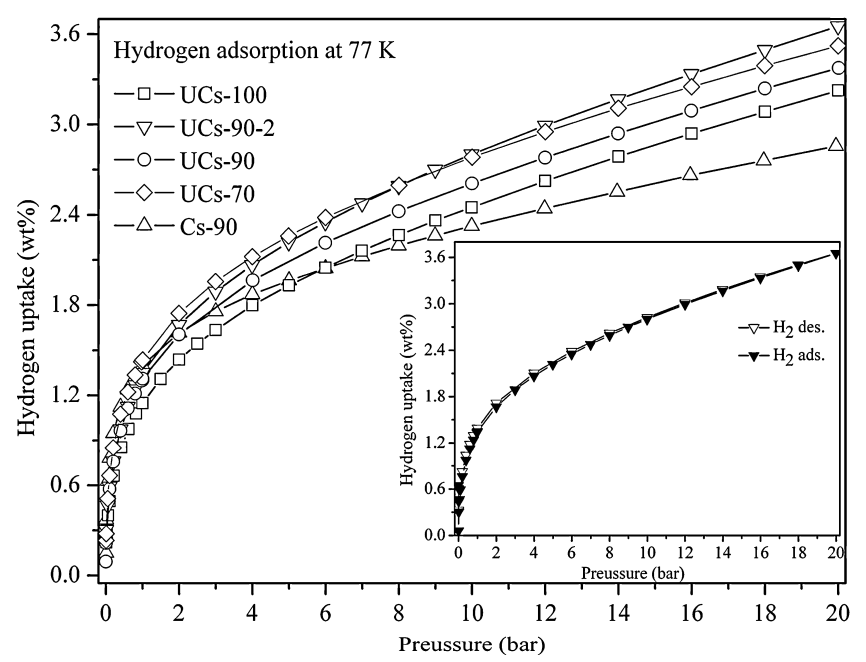

Fig. 6. $\mathrm{H}_{2}$ adsorption isotherms of carbons at $77 \mathrm{~K}$ and 20 bar. The inset is adsorption (Filled symbols) and desorption (Open symbols) isotherms for $\mathrm{H}_{2}$ at 20 bar on the UCs-90-2.

exhibiting the highest hydrogen storage uptake at 20 bar. It is clearly observed that the saturation is not achieved at 20 bar and the trajectory of isotherms suggests that a higher uptake is possibly obtained at the higher pressures. In contrast, UCs-70 has the highest micropore volume, displaying the highest uptake at 1 bar. This observation is in excellent consistent with previous studies which have already indicated that hydrogen uptakes in carbons have close relevancy with microposities [5,11,26,30]. However, it also should be noted that increased studies have already confirmed that it is not simply the overall surface areas and microporosities that determine hydrogen uptake in carbons but the surface areas associated with the 'optimal pores' of $6-9 \AA[5,14,46]$, which has been perfectly confirmed in this work. For example, the samples Cs-90, UCs-90, and UCs-90-2 exhibit a hydrogen uptake of 1.39, 1.30 , and $1.34 \mathrm{wt} \%$ at 1 bar, respectively, though the total surface areas and micropore volumes for Cs-90 are much smaller than other two samples. Particularly, UCs-100 with a higher micropore volume and surface area than Cs-90 also shows an uptake of $1.15 \mathrm{wt} \%$ at 1 bar. However, UCs-90-2 shows a larger hydrogen uptake than UCs-90 and Cs-90 at 20 bar. Therefore, we can infer that the presence of zeolites in the carbonization process can greatly enlarge the surface area and mesopore volume, and have a positive role in hydrogen storage at a higher pressure (e.g. 20 bar) but less effects at a lower pressure (e.g. 1 bar). It is reasonable from Fig. 3 that both the UCs-100 and UCs-90-2 have great quantities of large mesopores but Cs-90 has almost wholly micropores less than $1 \mathrm{~nm}$ only with little small mesopores, resulting in the much larger interaction energy of hydrogen molecules in these narrow micropores [11,44-46]. Moreover, it can be seen from Fig. 6 and Table 1 that the actual order of hydrogen uptake is roughly similar to that of the micropore volume, especially for pores less than $1 \mathrm{~nm}$. It is expected that carbons with a higher micropore volume have more accessible adsorption sites, resulting in the larger hydrogen storage capacities. However, it is interesting to note a fact that UCs-90-2 has the highest hydrogen uptakes at 20 bar and $77 \mathrm{~K}$, although its micropore volume was slightly lower than the UCs-70. As shown in Fig. 3, the PSD curve of UCs-90-2 also exhibits some macropores other than micro- and mesopores which will be work in the hydrogen storage at higher pressures, and thus the hydrogen uptake of UCs-90-2 is slightly higher than UCs-70 at 20 bar while slightly lower at 1 bar. In addition, the presence of zeolites in the carbonization process will inhibit the degree of graphitization to some extent, resulting in the increase of hydrogen storage uptakes. Therefore, 
synergistic effects between the graphitization of carbons and microporosities maybe play important roles in hydrogen storage.

\section{Conclusions}

In summary, we prepared sucrose-based carbons via templateassisted carbonization and investigated their $\mathrm{H}_{2}$ adsorption properties. The total pore volume and mesopore volume of carbons are almost proportional to the temperature. Furthermore, carbons obtained in the presence of zeolites exhibit much larger surface area and total pore volume than the ones obtained from the pure sucrose solution. Zeolite additives used in the carbonization process play an important role in developing mesoporisities, and carbons did not have the structural periodicity transferred from the zeolite template. The $\mathrm{H}_{2}$ storage capacity on UCs-902 is up to $3.6 \mathrm{wt} \%$ at $77 \mathrm{~K}$ and $20 \mathrm{bar}$, which is proportional to the surface areas and microporosities. Overall, our findings add and enrich some useful insights to some extent in designing suitable carbon-based materials for $\mathrm{H}_{2}$ storage. Moreover, the sucrose-based carbons with multi-pores have potential in the application of catalysis and electrode materials, though the surface modification is essential for further enlarging the levels of $\mathrm{H}_{2}$ storage.

\section{Acknowledgments}

We would like to thank the financial support from the "Hundred Talents Program" of Chinese Academy of Science (No. KJCX2-YWW34) and the National Natural Science Foundation of China (No. 21073216, 21173246). We also thank Prof. Yi Wang worked at School of Applied Physics and Materials, Wuyi University, for his assistance on Raman spectra measurements.

\section{References}

[1] L. Zhou, Progress and problems in hydrogen storage methods, Renew. Sust. Energ. Rev. 9 (2005) 395-408.

[2] J. Li, S. Cheng, Q. Zhao, P. Long, J. Dong, Synthesis and hydrogen-storage behavior of metal-organic framework MOF-5, Int. J. Hydrogen Energ. 34 (2009) 1377-1382

[3] J. Cai, Y. Xing, X. Zhao, Quantum sieving: feasibility and challenges for the separation of hydrogen isotopes in nanoporous materials, RSC Adv. 2 (2012) 8579-8586.

[4] L. Chen, R.K. Singh, P. Webley, Synthesis, characterization and hydrogen storage properties of microporous carbons templated by cation exchanged forms of zeolite Y with propylene and butylene as carbon precursors, Microporous Mesoporous Mat. 102 (2007) 159-170.

[5] K.M. Thomas, Hydrogen adsorption and storage on porous materials, Catal. Today 120 (2007) 389-396.

[6] L. Schlapbach, A. Züttel, Hydrogen-storage materials for mobile applications, Nature 414 (2001) 353-358.

[7] R. Orinakova, A. Orinak, Recent applications of carbon nanotubes in hydrogen production and storage, Fuel 90 (2011) 3123-3140.

[8] M.P. Suh, H.J. Park, T.K. Prasad, D.W. Lim, Hydrogen storage in metal-organic frameworks, Chem. Rev. 112 (2012) 782-835.

[9] H. Nishihara, T. Kyotani, Templated nanocarbons for energy storage, Adv. Mater. 24 (2012) 4473-4498.

[10] M. Sevilla, A.B. Fuertes, $\mathrm{CO}_{2}$ adsorption by activated templated carbons, J. Colloid Interface Sci. 366 (2012) 147-154.

[11] S.Y. Lee, S.J. Park, Preparation and characterization of ordered porous carbons for increasing hydrogen storage behaviors, J. Solid State Chem. 184 (2011) 2655-2660.

[12] D. Portehault, C. Giordano, C. Gervais, I. Senkovska, S. Kaskel, C. Sanchez, M. Antonietti, High-surface-area nanoporous boron carbon nitrides for hydrogen storage, Adv. Funct. Mater. 20 (2010) 1827-1833.

[13] S.J. Yang, J.H. Im, H. Nishihara, H. Jung, K. Lee, T. Kyotani, C.R. Park, General relationship between hydrogen adsorption capacities at 77 and $298 \mathrm{~K}$ and pore characteristics of the porous adsorbents, J. Phys. Chem. C 116 (2012) 10529-10540.

[14] Y. Xia, Y. Zhu, Y. Tang, Preparation of sulfur-doped microporous carbons for the storage of hydrogen and carbon dioxide, Carbon 50 (2012) 5543-5553.

[15] L. Wang, R.T. Yang, Molecular hydrogen and spiltover hydrogen storage on high surface area carbon sorbents, Carbon 50 (2012) 3134-3140.
[16] N.P. Stadie, J.J. Vajo, R.W. Cumberland, A.A. Wilson, C.C. Ahn, B. Fultz, Zeolitetemplated carbon materials for high-pressure hydrogen storage, Langmuir 28 (2012) 10057-10063.

[17] S.Y. Lee, S.J. Park, Synthesis of zeolite-casted microporous carbons and their hydrogen storage capacity, J. Colloid Interface Sci. 384 (2012) 116-120.

[18] F. Su, L. Lv, X.S. Zhao, Synthesis of nanostructured porous carbon, Int. J. Nanosci. 4 (2005) 261-268.

[19] M. Armandi, B. Bonelli, K. Cho, R. Ryoo, E. Garrone, Study of hydrogen physisorption on nanoporous carbon materials of different origin, Int. J. Hydrogen Energ. 36 (2011) 7937-7943.

[20] Y. Zhai, Y. Wan, Y. Cheng, Y. Shi, F. Zhang, B. Tu, D. Zhao, The influence of carbon source on the wall structure of ordered mesoporous carbons, J. Porous Mat. 15 (2008) 601-611.

[21] C. Ducrot-Boisgontier, J. Parmentier, L. Delmotte, J. Patarin, Influence of chemical vapour infiltration conditions of acetylene on the structural and textural properties of EMT-type zeolite nanocasted carbon replica, J. Mater. Sci. 44 (2009) 6571-6575.

[22] M. Inagaki, H. Orikasa, T. Morishita, Morphology and pore control in carbon materials via templating, RSC Adv. 1 (2011) 1620-1640.

[23] T. Kyotani, Control of pore structure in carbon, Carbon 38 (2000) 269-286.

[24] L.Y. Meng, S.J. Park, Influence of MgO template on carbon dioxide adsorption of cation exchange resin-based nanoporous carbon, J. Colloid Interface Sci. 336 (2012) 125-129.

[25] Y. Xia, Z. Yang, R. Mokaya, Templated nanoscale porous carbons, Nanoscale 2 (2010) 639-659.

[26] P. Guo, Y. Gu, Z. Lei, Y. Cui, X.S. Zhao, Preparation of sucrose-based microporous carbons and their application as electrode materials for supercapacitors, Microporous Mesoporous Mat. 156 (2012) 176-180.

[27] D. Günther, J. Beckmann, M. Schöneich, P. Schmidt, O. Klepel, Porous concrete as a template for the synthesis of porous carbon materials, Carbon 50 (2012) 3096-3098.

[28] F. Su, L. Lv, T.M. Hui, X.S. Zhao, Phenol adsorption on zeolite-templated carbons with different structural and surface properties, Carbon 43 (2005) $1156-1164$.

[29] R. Ryoo, S.H. Joo, S. Jun, Synthesis of highly ordered carbon molecular sieves via template-mediated structural transformation, J. Phys. Chem. B 103 (1999) 7743-7746.

[30] C. Guan, K. Wang, C. Yang, X.S. Zhao, Characterization of a zeolite-templated carbon for $\mathrm{H}_{2}$ storage application, Microporous Mesoporous Mat. 118 (2009) 503-507.

[31] S.H. Joo, S. Jun, R. Ryoo, Synthesis of ordered mesoporous carbon molecular sieves CMK-1, Microporous Mesoporous Mat. 44-45 (2001) 153-158.

[32] A. Wang, F. Kang, Z. Huang, Z. Guo, Preparation of natural zeolite templated carbon and its nanopore formation mechanism, New Carbon Mater. 22 (2007) $141-147$.

[33] G. Liu, F. Kang, B. Li, Z. Huang, X. Chuan, Characterization of the porous carbon prepared by using halloysite as template and its application to EDLC, J. Phys. Chem. Solids 67 (2006) 1186-1189.

[34] X. Yuan, W. Xing, S.P. Zhuo, Z. Han, G. Wang, X. Gao, Z.F. Yan, Preparation and application of mesoporous Fe/carbon composites as a drug carrier, Microporous Mesoporous Mat. 117 (2009) 678-684.

[35] O. Klepel, H. Strau, beta, A. Garsuch, K. Böhme, Several ways to produce porous carbon monoliths by template assisted routes, Mater. Lett. 61 (2007) 2037-2039.

[36] K. Matsuoka, Y. Yamagishi, T. Yamazaki, N. Setoyama, A. Tomita, T. Kyotani, Extremely high microporosity and sharp pore size distribution of a large surface area carbon prepared in the nanochannels of zeolite Y, Carbon 43 (2005) $876-879$.

[37] F.O.M. Gaslain, J. Parmentier, V.P. Valtchev, J. Patarin, First zeolite carbon replica with a well resolved X-ray diffraction pattern, Chem. Commun. (9) (2006) 991-993.

[38] Z. Yang, Y. Xia, R. Mokaya, Enhanced hydrogen storage capacity of high surface area zeolite-like carbon materials, J. Am. Chem. Soc. 129 (2007) 1673-1679.

[39] K.S.W. Sing, D.H. Everett, R.A.W. Haul, L. Moscou, R.A. Pierotti, J. Rouquerol, T. Siemieniewska, Reporting physisorption data for gas/solid systems with special reference to the determination of surface area and porosity, Pure Appl. Chem. 57 (1985) 603-619.

[40] M. Choi, R. Ryoo, Mesoporous carbons with $\mathrm{KOH}$ activated framework and their hydrogen adsorption, J. Mater. Chem. 17 (2007) 4204-4209.

[41] Z. Ma, T. Kyotani, A. Tomita, Synthesis methods for preparing microporous carbons with a structural regularity of zeolite Y, Carbon 40 (2002) 2367-2374.

[42] X.H. Song, W.S. Teo, K. Wang, Synthesis and characterization of activated carbons prepared from benzene CVD on zeolite Y, J. Porous Mat. 19 (2012) 211-215.

[43] A.C. Ferrari, J. Robertson, Interpretation of Raman spectra of disordered and amorphous carbon, Phys. Rev. B 61 (2000) 14095-14107.

[44] M. Sevilla, R. Mokaya, A.B. Fuertes, Ultrahigh surface area polypyrrole-based carbons with superior performance for hydrogen storage, Energy Environ. Sci. 4 (2011) 2930-2936.

[45] D. Saha, S. Deng, Adsorption equilibrium and kinetics of $\mathrm{CO}_{2}, \mathrm{CH}_{4}, \mathrm{~N}_{2} \mathrm{O}$, and $\mathrm{NH}_{3}$ on ordered mesoporous carbon, J. Colloid Interface Sci. 345 (2010) 402-409.

[46] Y. Chen, X. Cao, H. Zhu, Y. Liu, Preparation of a porous carbon from ferroceneloaded polyaniline and its use in hydrogen adsorption, Int. J. Hydrogen Energ. 37 (2012) 7629-7637. 